
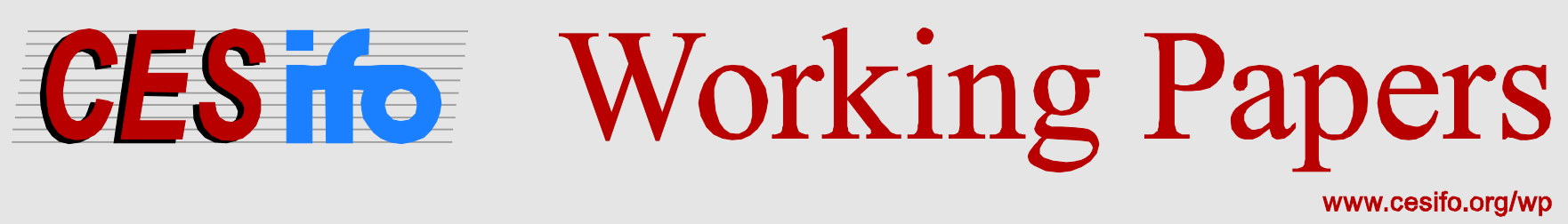

\title{
The Impact of R\&D Cooperations on Drug Variety Offered on the Market. Evidence from the Pharmaceutical Industry
}

\author{
Tannista Banerjee \\ Ralph Siebert
}

CESIFO WORKING PAPER NO. 4567

CATEGORY 11: INDUSTRIAL ORGANISATION JANUARY 2014

\footnotetext{
An electronic version of the paper may be downloaded

- from the SSRN website:

- from the RePEc website:

wWw.SSRN.com

www.RePEc.org

- from the CESifo website:

www.CESifo-group.org/wp
}

\section{CESifo}




\title{
The Impact of R\&D Cooperations on Drug Variety Offered on the Market. Evidence from the Pharmaceutical Industry
}

\begin{abstract}
Our study puts special attention to the fact that R\&D cooperations in the pharmaceutical industry are formed at different stages throughout the drug development process. We study if the timing to engage in R\&D cooperations in the pharmaceutical industry has different impacts on the technology and product markets. Using a comprehensive dataset on the pharmaceutical industry, and estimating a heterogeneous treatment effects model (Heckman et al., 2006) our results show that R\&D cooperations formed at the early stages increase the number of R\&D projects and the number of drugs launched on the product market. Most interestingly, late stage R\&D cooperations significantly reduce the number of drugs launched on the market, even though they increased firms' activity in the technology markets. This result highlights the fact that firms re-optimize their drug development portfolio to avoid wasteful duplication and cannibalizing the sales of the jointly developed drug in R\&D cooperations. Our study show that firms cooperating in late stage collaborations re-optimize their individual drug development portfolios, which significantly reduces the number of drugs offered on the market.
\end{abstract}

JEL-Code: L240, L250, L650, D220.

Keywords: drug development, dynamics, co-development, pharmaceutical industry, product variety, product market competition, Research and Development cooperation.

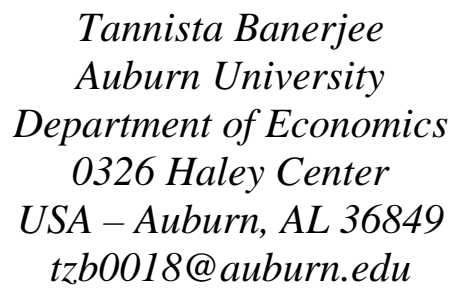

Tannista Banerjee

niversity

artment of Economics

USA - Auburn, AL 36849

tzb0018@auburn.edu

\author{
Ralph Siebert \\ Purdue University \\ Department of Economics \\ Krannert School of Management \\ 403 West State Street \\ USA - West Lafayette, IN 47907-2056 \\ rsiebert@purdue.edu
}

December, 2013

We thank seminar participants at Purdue University and Auburn University. We especially thank Jack Barron, Jeremiah Harris and Stephen Martin for their helpful discussions and valuable suggestions. All errors are our own. 


\section{Introduction}

In many industries the development of new products and processes is an important aspect which determines economic growth as well as consumer welfare. For example, in the pharmaceutical industry, a successful completion of drug development processes increases the likelihood of curing symptoms and diseases such as Alzheimers, Cancer, HIV, and Parkinsons. Hence, the introduction of new drugs on the markets has a significant impact on quality of life and life expectancy.

The process of developing new drugs is characterized by many obstacles, such as financial constraints, uncertainties, as well as increasing research and development costs. Research and development (R\&D) cooperations (e.g., joint ventures and licensing agreements) are an important instrument to overcome those innovation impediments, as they allow firms to exploit synergy effects and to share R\&D costs ${ }^{1}$.

The drug development process in the pharmaceutical industry is characterized by several research stages or phases which need to be successfully completed before a drug receives permission by the Food and Drug Administration to be launched on the market ${ }^{2}$. It is common in the industry to separate the development process into two distinct stages, i.e., the early stage (Discovery, Lead Molecule or Pre-Clinical stage) and the late stage (development and testing), see e.g., DiMasi et al. (1991 and 2003). The requirements, aims and scope of a research project are specific to the early and late research stages.

At the early stages, research projects concentrate on basic research questions such as finding a new molecule structure. Scope economies and learning from knowledge spillovers are important characteristics during those stages, see e.g., Henderson and Cockburn (1996)

\footnotetext{
${ }^{1}$ Prominent empirical studies on research cooperations focus on the impact of R\&D cooperations on R\&D investments, see for example Sakakibara (2002), Cassiman and Veugelers (2002), Irwin and Klenow (1996), and Roller, Siebert and Tombak (2007), Nicholson et al. (2003), Higgins and Rodriguez(2006), Arora et al. (2009), Nicholson et al. (2003) and Grabowski and Margaret (2012) among others. The majority of studies finds that R\&D cooperations are an appropriate instrument to overcome innovation impediments and increase R\&D activities. These findings encouraged many countries to establish research programs that support the formation of research cooperations, mainly to keep up with increased international competition in R\&D. Examples are the National Cooperative Research Act enacted by the U.S., the MITI by Japan, as well as EU framework programs, ESPRIT and EUREKA in Europe, among many others.

${ }^{2}$ Table 1 provides a list of different research phases. See also Section 3 for a more detailed description of the industry and the research phases.
} 
and Nesta and Saviotti (2005). Once the research projects approach the late stages they require experience related to empirical testing of the drug on different populations (applied research), involving more human subject management, drug safety testing, and passing clinical trials in order to launch new drugs on the markets.

Firms engage in R\&D cooperations at various stages of the drug development process. While some $R \& D$ cooperations are formed at the early stage of the research process, other $R \& D$ cooperations are established at the late stages, after the $R \& D$ projects passed the early stages with individual research efforts ${ }^{3}$.

Our study concentrates on the following questions: First, which arguments determine firms' decisions to form R\&D cooperations at different stages of the development process? Second, what is the impact of R\&D cooperations formed at different research stages on firms' activities in the R\&D and drugs launched on the market?

Only few theoretical studies consider the formation of research cooperations at different stages of the development process, see e.g., Grossman and Shapiro (1986 and 1987). We are not aware of any empirical studies which elaborate on the incentives to form R\&D cooperations at different research stages and, more importantly, to evaluate the different impacts on firms' R\&D and drugs launched on the markets.

An example for an early stage R\&D cooperation is the following: In November of 2011, the pharmaceutical companies Takeda Ltd. and XOMA Ltd. signed a R\&D cooperation at the early stage of drug development process. The aim of the $R \& D$ cooperation was to overcome its financial constraints and to jointly develop a monoclonal antibody in the oncology market. The R\&D cooperation helped firms to overcome innovation impediments, to promote R\&D activity and to eventually launch new drugs on the product market.

A well known R\&D cooperation formed at the later stages of the development process involved the companies Tanox, Novartis and Genentech. The aim of the cooperation was to select and develop anti-Immunoglobulin E antibodies. In 2003, the cooperation eventually received approval by the Federal Drug Administration for their newly developed

\footnotetext{
${ }^{3}$ Table 3 shows the number of R\&D cooperations formed at different stages. We provide more detailed information on $\mathrm{R} \& \mathrm{D}$ cooperations formed throughout different research stages in Section 3.
} 
drug XOLAIR to treat severe allergies and asthma. Through court orders Tanox was forced by its cooperating partners to cease its independent development of other antiImmunoglobulin E antibodies (including CGP 56901) for treating the same disease. The cooperation partners argued that the drug development violated their R\&D cooperation agreement $^{4}$.

The example illustrates that R\&D collaborators have the opportunity to re-optimize their drug development portfolio and eventually discontinue some of their individual R\&D projects, either willingly or due to the pressure from cooperators. In response to their jointly developed drugs firms re-optimize their drug development portfolios and discontinue the individual development of those drugs, which represent close substitutes to the newly developed drugs, to avoid cannibalizing the sales of the jointly developed drugs. Therefore, conclusive inferences about the ultimate impact of $R \& D$ cooperations on the drug variety offered on the market is driven by several factors such as the likelihood that drugs successfully pass the research stage, overcoming innovation impediments, and the fact that firms respond to jointly developed drugs and re-optimize their drug development pipeline.

Our study focuses on the pharmaceutical industry as it characterizes a natural object to focus on the dynamic R\&D process and to investigate the impact of $R \& D$ cooperations on product variety for several reasons. First, drugs must successfully pass multiple clinical or research stages before being launched on the market. This enables us to track the dynamics of the R\&D process and the timing of engaging into $R \& D$ cooperations. Second, new drug applications must be approved by the Federal Drug Administration. Therefore, the number of new products introduced into the market is publicly documented, which allows us to establish a reliable database on the number of products in the market.

Our study uses firm-level information on $R \& D$ cooperations, firms' research agendas and their drugs offered on the market from 1993-2011. In evaluating the impact of R\&D cooperations, we face a missing data problem. We observe firms that either cooperated at the early stage or the late stage, or did not cooperate at all, but we do not observe the

\footnotetext{
${ }^{4}$ See also Sammi (2006) for a detailed discussion in this area.
} 
counterfactuals. To overcome this problem, we apply a switching regression framework and estimate the "treatment effect" of early and late stage R\&D cooperations on firms activity in the technology and product market.

Previous literature on estimating treatment effects pointed out two associated potential biases, i.e., the pre-treatment heterogeneity bias or selection bias, and the heterogeneous treatment effect bias $^{5}$.

The pre-treatment heterogeneity refers to firms self-selecting themselves into early/late stage $R \& D$ cooperations based on firm-level attributes. In our case, it relates to the fact that observed firm-level attributes, such as technology and product market level of activity, determine firms' decision to form R\&D cooperations. In addition, we account for unobserved firm-level attributes such as managerial ability, absorptive capacity, etc., which affect firms' decision to participate in R\&D cooperation. Finally, we account for the fact that firms' participation in $\mathrm{R} \& \mathrm{D}$ cooperation also has an expected impact on future positions in the technology and product markets. Ignoring this self-selection incentive results in a potential selection bias. For example, R\&D cooperation seemingly appears to increase technology and product market level of activity, simply because cooperating firms were already more research and production intensive than non-cooperating firms, before they selected themselves into R\&D cooperation. Hence, we apply an identification strategy based on instrumental variables to control for a potential self selection bias ${ }^{6}$.

The heterogeneous treatment effect bias relates to the fact that firms sort themselves on an expected profit gain to improve their positions in the technology and product markets. For example, firms with a strong R\&D market presence are able to benefit more from additional knowledge due to higher absorptive capacity. Moreover, production intensive firms might achieve higher gains in launching new drugs. Hence, we allow the impact of R\&D cooperation to vary across firms.

\footnotetext{
${ }^{5}$ See also Angrist and Krueger (1999), Heckman, Urzua and Vytlacil (2006), Morgan and Christopher (2007), Dehejia and Wahba (2002), and Brand and Xie (2010), Brand and Thomas (2012) and Pais (2011).

${ }^{6}$ It is important to account for firms incentives to collaborate depending on their technology and product market positions in order to thoroughly investigate the impact of R\&D collaborations on technology and product market level of activity, see e.g. Roller, Siebert and Tombak (2007).
} 
We estimate a heterogeneous treatment effect model, adopting the estimator suggested by Heckman, Urzua, and Vytlacil $(2006)^{7}$.

Our results confirm that firms select themselves into early and late stage cooperations depending on their level of activity in the R\&D and the product market. While early stage $R \& D$ cooperations are formed among less research intensive firms, late stage $R \& D$ cooperations are more common for firms, which are more active in technology and product markets.

Our results also show that early and late stage R\&D cooperations differ in their impact on the technology and product markets. More specifically, early stage cooperations allow firms to benefit from economies of scope, which increases R\&D activity by $21 \%$. The gains in the technology markets will be transmitted to the product market and increases the number of drugs offered on the market. We also find that the impacts on technology and product markets increase over time. Turning to the results on the impact of late stage R\&D cooperations, we find only a minor improvement in firms' activity in the technology market, which is not sustainable over time. Most importantly, our study shows that late stage $R \& D$ cooperations reduce the number of drugs offered on the product markets.

The remainder of the paper is organized as follows. The next section surveys the relevant literature. In Section 3, we provide an industry description. Section 4 presents a description of the data sources and the variable definitions. Section 5 discusses the empirical model and the estimation procedure. Section 6 presents the empirical results. We conclude in Section 7.

\section{Literature overview}

Research cooperations have frequently been analyzed in the literature and are considered to have socially beneficial impacts such as internalizing research externalities or avoiding wasteful duplications in research. In the pharmaceutical industry, several studies showed

\footnotetext{
${ }^{7}$ Estimators such as fixed effects and difference in difference eliminate the selection bias, but not the treatment effect heterogeneity bias (Angrist and Krueger, 1999).
} 
that $\mathrm{R} \& \mathrm{D}$ cooperations increase the likelihood of developing new drugs. For example, Arora et al. (2009), Danzon et al. (2005) and Nicholson et al. (2003) show a positive effect of R\&D collaborations on clinical trial successes. Powell et al.(1999) shows a positive effect of $\mathrm{R} \& \mathrm{D}$ collaboration on $\mathrm{R} \& \mathrm{D}$ and the production of patents. Lerner and Tsai (2000) show that R\&D collaborations generate more approved drugs under more favorable financing conditions. In a related context, Ornaghi (2009) studies the effects of mergers in the pharmaceutical industry on firms' $R \& D$ activity and finds that merged companies reduce their $R \& D$ activity.

As mentioned above, drug development projects underly an inherently dynamic process. A new drug must successfully pass multiple phases before it receives permission by the Food and Drug Administration to be launched on the product market. Throughout the research process, companies invest enormous amounts in scientific knowledge. Empirical studies in the pharmaceutical industry highlight the relevance of economies of scope and scale throughout different stages of the R\&D process, see e.g., Henderson and Cockburn (1996 and 2001) and Nesta and Saviotti (2005). Previous literature on R\&D cooperations has shown that economies of scope and spillovers increase R\&D investments. Moreover cost sharing arguments and the reduction in R\&D costs or fixed costs increase the number of products offered on the market, see e.g., Salop (1979) and Lancaster (1979).

To date, only a few empirical studies account for the timing of forming research cooperations throughout the R\&D process. For example, Siebert and von Graevenitz (2012) investigate firms incentives to form a licensing agreement at the beginning of the research process or to exchange their inventions after the research has been completed unilaterally. Oxley and Sampson (2004) and Erkal and Minehart (2008) have shown that firms should be hesitant to form R\&D cooperations at the late stages. Lerner and Merges (1998) focus on partner matches between firms in forming research cooperations. They find that smaller firms frequently have incentives to form cooperations with larger companies at the early stages of the drug development process. Small biotechnology companies frequently lack resources to complete the entire R\&D process for the innovation of a new drug. They 
develop a new drug molecule and search for sponsors to complete the development process (Powell and Brantley, 1992).

In a related context, the theoretical work by D'Aspremont and Jacquemin (1988) shows that Research Joint Ventures spend more on R\&D and generate higher profits if technological spillovers are sufficiently high; see also Spence (1984) and Katz (1986) for similar results. The study by Kamien, Muller, and Zang (1992) shows that firms' investments and their incentives to engage in research cooperations depend on the degree of spillovers and their product relatedness. For example, if firms face high spillovers in the technology market, but operate in different product markets (i.e., their products are totally differentiated), cooperations lead to an increase in R\&D investments. The reason is that information spilling towards a rival does not encompass any competitive externality on a firms profits as firms operate in different product markets. Hence, firms do not have to be concerned that rivals gain a free ride on their own investments which results in lower profits via business stealing. In contrast, if firms offer similar products on the market, i.e., if the degree of product differentiation is low, firms exert negative externalities on each other via business stealing which lowers their profits. Gugler and Siebert (2007) consider the interdependence in technology and product markets to explain the formation and impact of mergers on firm and market performance in the semiconductor industry.

Policy debates often raise concerns about potential anti-competitive collusive implications of R\&D cooperations ${ }^{8}$. In fact, policy makers devote special attention to the question if $\mathrm{R} \& \mathrm{D}$ cooperations result in price fixing agreements ${ }^{9}$. Seminal empirical studies, e.g., Goeree and Helland (2012), Roeller et al. (2013) as well as Suetens (2008), investigate if $\mathrm{R} \& \mathrm{D}$ cooperations facilitate price fixing behavior in the product market ${ }^{10}$. However, price fixing is one example where cooperating firms in $R \& D$ cause a potentially harmful impact

\footnotetext{
${ }^{8}$ See also Jorde and Teece (1990) and Shapiro and Willig (1990).

${ }^{9}$ Many cartels were formed in the past in the pharmaceutical industry. Perhaps the best known price fixing case in the pharmaceutical industry involved Hoffmann-La Roche Ltd and BASF which plead guilty in 1999. In a worldwide conspiracy the parties fixed prices and allocated sales. The companies paid a fine of close to 1 billion U.S. dollars. See also http://www.justice.gov/opa/pr/1999/May/196at.htm for further information on this case.

${ }^{10}$ Martin (1995) and Cabral (2000) provide theoretical evidence of tacit product market collusion arising from $\mathrm{R} \& \mathrm{D}$ cooperations.
} 
on the product market, and there are other alternatives that deserve empirical attention. In this regard, our study contributes to the question if $\mathrm{R} \& \mathrm{D}$ cooperations cause potential anti-competitive concerns for product market level of activity.

\section{Industry description}

The pharmaceutical industry is a research intensive industry. Pharmaceutical companies face a permanent pressure to discover new drugs for improving the quality of human life and to target diseases such as AIDS, cancer, Alzheimers etc. The associated returns from launching a new drug are frequently extraordinarily high, which increases firms incentives to receive a patent on a specific drug. Moreover, an increased global competition puts more pressure on firms to develop drugs in a shorter time period. As a result, firms invest an enormous amount of money in research and development.

In order to launch a new drug on the market, the drug must successfully pass seven stages before it is granted an approval by the Food and Drug Administration, see Table 1 in the Appendix. The "Discovery" and "Lead Molecule or Pre-clinical" stages, involve research on identifying potential molecules. The new compound is also extensively tested for toxicity in animals. In "Phase I" the compound is tested for safety on healthy human volunteers; in "Phase II" the drug is tested on a small group of patients to establish efficacy; and in "Phase III" the compound is tested on a larger number of more diverse patients to establish both safety and efficacy.

The literature separates the drug development process into two distinct stages, i.e., the early and the late stage ${ }^{11}$. The requirements, expertise, aim and risks of the development process are fundamentally different between early and late stages. The aim of the drug development at the early stage is to explore a compound that demonstrates some desirable effect on either an animal or chemical screen. For example, firms search for compounds that can make obese rats thinner or that can block the action of an enzyme that is known

\footnotetext{
${ }^{11}$ See the description of the drug development guidelines provided by FDA http://www.fda.gov/Drugs/DevelopmentApprovalProcess/default.htm and the analysis by Henderson and Cockburn (1996).
} 
to regulate metabolic activity. The early stages concentrate more on laboratory research, explore the chemical stability of the molecules and invent promising molecules that can treat target diseases. The public goods aspect of knowledge ${ }^{12}$ takes place through the synergy of cooperative partners' joint knowledge base. Hence, economies of scope in the form of internal as well as external knowledge spillovers are important aspects during the early research stages.

In contrast, the aim of the late stage drug development process is to explore the degree to which a particularly promising compound is safe and effective for humans. Late stages concentrate more on the development side of the process. Research projects at the late stages deal with the dosage determination, side effects identification, duration of use etc.

After completing the development stages, the firm submits its new drug application (NDA) to the Food and Drug Administration (FDA), which eventually decides on approval of the application. The FDA requires evidence of a drug's effectiveness, through thoroughly-controlled clinical investigations. Pharmaceutical firms receive Intellectual Property Rights in the form of patents for the drugs introduced into the product market; the length of patent protection lasts on average 15 years. Table 2 presents the number of new drug approvals between 1993 and May 2011. NDA approvals vary a lot between different years and declined in the last few years.

The pharmaceutical industry is divided into 18 therapeutic areas (technological markets) ${ }^{13}$, see Table 3 in the Appendix. The disease areas (product markets) are also divided into same 14 different markets. The classifications on the therapeutic and disease areas are commonly used in the health literature, by the Food and Drug Administration and by BioPharm Insight. Table 4 shows that the maximum number of technology (Tech) and disease (Product) market areas in which pharmaceutical companies are active are 18 and 14, respectively. The technology market level of activity ( $T M A)$ measures a firm's research activities in different therapeutic areas ${ }^{14}$. Similarly, the product market level of

\footnotetext{
${ }^{12}$ As mentioned by Henderson and Cockburn (1996)

${ }^{13}$ these areas are Cancer; Cardiovascular; Central Nervous System; Dermatology; Diagnostic/Imaging agent/Delivery; Eye and ear; Gastrointestinal; Genitourinary; Hematological; HIV; infection; Hormonal system; Immune system; Infectious disease; Musculoskeletal; Nephrology; Pain; Respiratory.

${ }^{14}$ The variable definitions are explained in more detail in Section 4.
} 
activity $(P M A)$ represents a firm's strength in different disease areas.

R\&D cooperations are considered as an appropriate and popular instrument for firms to overcome innovation impediments. Our dataset shows that 3,756 R\&D cooperations took place between 1993 and May 2011, see Table 3 in the Appendix ${ }^{15}$. If the NDA is approved by FDA after cooperation, both firms share the patent right of the drug according to their pre-specified contract.

The table shows the sharp discrepancies in the number of cooperations between technology areas. For example, the technology area cancer has the largest number of cooperations (781), followed by infectious diseases (404), which includes HIV. One reason for finding a large variation in cooperations between technology areas is that the areas are characterized by different financial requirements, different technological spillovers, and different relationships between firms in the disease areas.

In formulating firms' decisions on cooperating in $R \& D$, it is important to note that the $R \& D$ process in the pharmaceutical industry is characterized by a high degree of uncertainty and is difficult to foresee. For example, several drug development projects such as Viagra, Cialis and Aspirin had a different original goal, and the uncertainty in R\&D eventually changed the application of the drugs. Consequently, firms' decisions to engage in early and late stages may alter and considered to be independent throughout the research process.

Table 5 shows the descriptive statistics of firm characteristics that participated in early and late stage $R \& D$ cooperations. It is frequently claimed that $R \& D$ cooperations are associated with enormous transactions costs, which involve specifically designed contracts, managerial expertise, lawyers, partner matching etc. Since early and late stage R\&D cooperations are different in nature, they are also characterized by specific organizational, contractual and managerial efforts. Hence, the associated transaction costs are specific to the types of cooperation. We account for the fact that transaction cost decline as firms accumulate more experience from participating in early and late stage R\&D cooperations,

\footnotetext{
${ }^{15}$ The information is taken from our established database, which contains firm-level information on R\&D cooperations, drugs under development and drugs offered on the market. All information is distinguished by technology and disease areas. Details on the data sources can be found in Section 4
} 
see also Siebert and von Graevenitz (2010).

\section{Data sources and variable definitions}

Since the main interest of our empirical study is to estimate the impact of early and late stage R\&D cooperations on firms' level of activity in the technology (therapeutic) and product market (disease) areas, we use detailed firm-level data on the Biotechnology and Pharmaceutical industry over time. Our database is constructed from a variety of different data sources, of which the main part is provided by BioPharm Insight. In the following, we provide a thorough description of the data sources and the definitions of variables we use in our empirical model ${ }^{16}$.

\subsection{Early/late stage $\mathbf{R} \& \mathbf{D}$ cooperations: $d_{i r t}^{Y}$}

Our study evaluates the associated impact of $\mathrm{R} \& \mathrm{D}$ cooperations on the drug development process as well as the number of drugs offered on the market. In our context, a proper evaluation requires a distinction between different types of $R \& D$ cooperations, and to concentrate on those cooperations that allow for potential synergy effects in research. Therefore, we concentrate our study on (ex ante) R\&D cooperations, in which firms jointly invest and work in $R \& D^{17}$. Consequently, we exclude $R \& D$ cooperations in which only one company discovers a new drug molecule without gaining any synergy effects from collaborators, such as (ex post) R\&D cooperations (already discovered inventions are transferred to other firms) and product development deals (R\&D activities are outsourced to other firms).

Our database on R\&D cooperations is provided by the BioPharm Insight research cooperations, which collected the original information from the U.S. Securities and Exchange Commission filings, a global network of journalists and expert industry research

\footnotetext{
${ }^{16}$ Further information on the data can also be found on BioPharm Insight's website, see http://www.biopharminsight.com/biopharm_insight.html.

${ }^{17}$ In (ex ante) $R \& D$ cooperations firms decide on joining $R \& D$ cooperations before the invention has been made.
} 
analysts. As mentioned above, we account for dynamics in the drug development process and firms' decision when to join R\&D cooperations. Firms decide whether to engage into an early stage $R \& D$ cooperation, a late stage $R \& D$ cooperation, or not to engage in either one. Our database contains information on which firms formed R\&D cooperations at what time, at which research stage ${ }^{18}$. The $R \& D$ cooperations are classified into 18 different drug development (or therapeutic) areas and disease areas.

We formulate dummy variables $\left[d_{i r t}^{Y},(Y=\right.$ Early, Late $\left.)\right]$, which take on a value of 1 if firm $i$ formed a R\&D cooperation at the early or late stage of the drug development process, in a certain therapeutic area $(r)$, in time period $t$. Otherwise, the dummy takes on a value of zero. $d_{i r t}^{Y}$ measures degree of the economies of scope.

\section{Early/late stage experience: $E X P_{i r t}^{Y}$}

As mentioned above, we account for transaction costs associated to early and late stage cooperations. We use a proxy, the number of past early and late stage R\&D cooperations, to account for firms' experience ${ }^{19}$. Hence, firm $i$ 's experience in signing early and late stage cooperations agreements in therapeutic market $r$ in year $t$ is defined as,

$$
E X P_{i r t}^{Y}=\sum_{s=1}^{t-1} Y_{i r s} ;,(Y=\text { Early, Late })
$$

where $Y_{\text {irs }}$ is the number of early stage or late stage cooperations a firm signed in year $s$.

\subsection{Technological market level of activity: $T M A_{i r t}$}

Firms' strength of research capabilities vary across different therapeutic areas. We account for firms' expertise in different therapeutic areas and establish a measure, technological market level of activity, that evaluates how a firm's technology or drug market portfolio

\footnotetext{
${ }^{18}$ Changes in company names over time via mergers and takeovers are corrected for.

${ }^{19}$ See also Siebert and von Graevenitz (2010).
} 
evolves over time,

$$
T M A_{i r t}=\widetilde{z}_{i r t}+\sum_{s=1}^{t-1}(1-\delta)^{s} \widetilde{z}_{i r t} .
$$

The measure accounts for the number of research projects $\left(\widetilde{z}_{\text {irt }}\right)$ undertaken by firm $i$ in therapeutic area $(r)$ in period $t$. Since research in the pharmaceutical industry is a highly paced process, the value of research knowledge quickly depreciates over time. To account for the depreciation of a firm's knowledge base over time, we discount a firm's drug portfolio over time, and apply a perpetual inventory method with a depreciation rate of $\delta=0.15 \%$, see also Griliches and Mairesse (1984), Hall (1993), etc.

\subsection{Product market level of activity: $P M A_{\text {irt }}$}

Similar to the therapeutic market level of activity, pharmaceutical firms have different strengths and expertise in launching new drugs in different disease or product market areas. We construct a measure called product market level of activity to account for firms' expertise in different disease areas (r) over time. The measure refers to the number of approved drugs a firm launched in different disease areas, and is specified as follows ${ }^{20}$ :

$$
P M A_{\text {irt }}=\widetilde{p}_{\text {irt }}+\sum_{s=1}^{t-1}(1-\delta)^{s} \widetilde{p}_{i r t} .
$$

The total number of approved drugs for firm $i$ in disease area $(r)$ in period $t$ is denoted as the product market portfolio $\widetilde{p}_{i r t}$. Since a drug is offered on the market for several years, its market value as well as the experience associated with launching a new drug depreciates over time. Again, we apply the perpetual inventory method with a depreciation rate of $\delta=0.15 \%$.

\footnotetext{
${ }^{20}$ Information about the name of the approved drug, the approval date, the company name and the disease area is released by the FDA on the Drugs@FDA webpage, see http://www.accessdata.fda.gov/scripts/cder/drugsatfda/index.cfm. BioPharm Insight collects this drug approval data from the FDA. See also Table 3 for the number of drug approvals by year.
} 


\subsection{Diversification in product and technology markets: Product $_{i t}$} and Tech $_{i t}$

Firms have the opportunity to absorb new knowledge from forming R\&D cooperations. Firms being active in multiple therapeutic areas have the opportunity to transfer their knowledge gained in one therapeutic area to another therapeutic area, and benefit from a larger scope in $R \& D$, which increases their incentives to form $R \& D$ cooperations. The diversification variable is a tool for internal knowledge transfer and therefore the key for economies of scope. We control for this diversification variable because we want to identify the economies of scope and the effect solely arising from the R\&D cooperations. We construct a variable $\left(\right.$ Tech $\left._{i t}\right)$, which refers to the number of different therapeutic areas in which firm $i$ operates. According to the definition of the therapeutic areas in Table 2, the variable can take on a value between 1 and 18. A higher value refers to a larger scope in $\mathrm{R} \& \mathrm{D}$ and higher potential technological spillovers.

We apply the same rationale to the product market. Firms operating in several disease areas have a higher incentive to engage in $\mathrm{R} \& \mathrm{D}$ cooperations as the innovations can be applied to drug testing in different disease areas. We establish a variable that accounts for firms' multi-market character. The variable $\left(\right.$ Product $\left._{i t}\right)$ indicates the number of different disease areas in which a firm operates ${ }^{21}$.

\section{Empirical model specification}

Based on an underlying theoretical framework, which is delegated to the appendix, we specify our regression equations to estimate the impact of early and late stage $R \& D$ cooperations on technology and product market activity.

As firms select themselves into R\&D cooperations based on anticipated gains and costs

\footnotetext{
${ }^{21}$ Finally, note that financial information taken from firms' balance sheet information is a potential variable that could have been included in our empirical study. The drawback of including this information, however, is that we had to condition our empirical study on the fact that firms are public and we would lose the majority of observations. We therefore control for firm-level fixed effects to capture the financial aspects in our model.
} 
of participation, an ordinary least square regression may result in an upward bias. Following Heckman, Urzua, and Vytlacil (2006), we apply a heterogeneous treatment effects model to control for two potential biases, i.e., (i) the pre-treatment heterogeneity bias or selection bias, and (ii) the heterogeneous treatment effect bias ${ }^{22}$. The heterogeneous treatment effects model consists of a selection and an outcome equation. The selection equation describes firms' endogenous selection to form early and late stage R\&D cooperations in market $r$ in year $t$. According to the introduced dummy variables $\left[d_{i r t}^{Y},(Y=\right.$ Early, Late $\left.)\right]$ in the previous section, we formulate a latent variable $d_{i r t}^{Y *}>0$, iff the dummy variable $d_{i r t}$ takes on a value of 1 , and $d_{i r t}^{Y *}<0$, iff the dummy variable $d_{i r t}=0$. The selection equation is specified as follows ${ }^{23}$ :

$$
\begin{aligned}
& d_{i r t}^{Y *}=\gamma_{1} P M A_{i r t}+\gamma_{2} T M A_{i r t}+\gamma_{3} E X P_{i r t}^{\text {Early }}+\gamma_{4} E X P_{i r t}^{\text {Late }}+\gamma_{5} \text { Tech }_{i t}+\gamma_{6} \text { Product }_{i t} \\
& +\gamma_{7} \text { mean }\left(P M A_{i r t}\right)+\gamma_{8} \text { mean }\left(T M A_{i r t}\right)+\sum_{t=1}^{19} \gamma_{9 t} \text { Time }_{i t}+u_{i r t}^{Y}+c_{i r}^{Y}
\end{aligned}
$$

where the firm's decision to join early or late stage cooperations is dependent on the firm's activity in the therapeutic areas $\left(T M A_{\text {irt }}\right)$ and the product market areas $\left(P M A_{\text {irt }}\right)$. The participation decision depends on experience $\left(E X P_{\text {irt }}^{\text {Early }}\right.$ and $\left.E X P_{\text {irt }}^{\text {Late }}\right)$ and the diversification variables $\left(\right.$ Tech $_{i t}$ and Product $\left.{ }_{i t}\right)$, which serve as the exclusion restriction to identify the model. Regarding the experience variables, we build on the transaction cost argument, i.e., that the specific $\mathrm{R} \& \mathrm{D}$ cooperations are associated with significant organizational, contractual and administrative efforts that diminish the more expertise a

\footnotetext{
${ }^{22}$ The pre-treatment heterogeneity refers to firms self-selecting themselves into early/late stage R\&D cooperation due to firm-level heterogeneities such as managerial ability and absorptive capacity. The post-treatment heterogeneity accounts for different impacts after firms selected themselves into R\&D cooperations.

${ }^{23}$ As mentioned in the description of our underlying theoretical model (see Appendix) we formulate the decision to form an early or late stage $R \& D$ cooperation on an individual firm-level rather than on a firm-pair level. A decision based on the value of firm-pairs would implicitly assume that firms cooperated in the R\&D as well as the product market, which is not encourage from an antitrust perspective
} 
firm collected. We therefore use the number of previous early and late stage cooperations as an instrument which has an impact on the likelihood of forming a cooperation, but does not directly impact the position in the therapeutic and product market. They rather indirectly impact the outcome equations via $R \& D$ cooperations. We use the diversification variables as additional instruments, since they reflect different potential learning and synergy effects associated to engaging into early and late stage R\&D cooperations. We allow for unobserved heterogeneity which enters the equation above as follows: $\varepsilon_{i r t}^{Y}=c_{i r}^{Y}+$ $u_{i r t}^{Y}, Y=$ Early, Late, where $c_{i r}^{Y}$ is the unobserved heterogeneity and $u_{i r t}^{Y} \approx N(0,1), Y=$ Early, Late, are the idiosyncratic error terms. Following Wooldridge (2002), we include the time averages of the technology, $[\operatorname{mean}(T M A)]$, and product markets, $[\operatorname{mean}(P M A)]$ to control for unobserved firm-specific heterogeneity. Equation (1) is estimated using a probit estimation ${ }^{24}$.

In a next step, we estimate the outcome equations to evaluate the impact of early and late stage $\mathrm{R} \& \mathrm{D}$ cooperations $\left(d_{i r t}^{Y}\right)$ on the therapeutic market and the product market. The outcome equation which measures the impact on the product market $\left(P M A_{i r t+j}\right)$ is specified as follows,

$$
\begin{aligned}
& P M A_{i r t+j}=\alpha_{1}+\alpha_{2} d_{i r t}^{Y}+\alpha_{3} P M A_{i r t}+\alpha_{4} T M A_{i r t}+\alpha_{5} d_{i r t}^{Y} *\left(P M A_{i r t}-\operatorname{mean}\left(P M A_{i r t}\right)\right) \\
& +\alpha_{6} C T_{i t}^{1}+\alpha_{7} C T_{i t}^{0}+\sum_{i=8}^{27} \alpha_{t} \text { Time }_{i t}+\nu_{i r t}
\end{aligned}
$$

where $j=1,2 ; Y=$ Early, Late. The equation is specified in autoregressive form, where the impact on the product market $\left(P M A_{i r t+j}\right)$ depends on the current positions in the technology market $\left(T M A_{\text {irt }}\right)$ and the product market $\left(P M A_{\text {irt }}\right)$. Note, we account for different time lengths $j=1,2$ when measuring the impact on the product

\footnotetext{
${ }^{24}$ To account for heterogeneity we follow the procedure as suggested by Heckman, Urzua, and Vytlacil (2006). See also Cerulli (2012) for a description.
} 
market. The dummy variable $\left(d_{i r t}^{Y}\right)$ measures to what extent early and late stage R\&D cooperations cause any deviation from the autoregressive trend. In following Heckman, Urzua, and Vytlacil (2006) we account for the ex post heterogeneity and incorporate an interaction term between the $\mathrm{R} \& \mathrm{D}$ cooperation and the product market activity $d_{i r t}^{Y} *\left(P M A_{i r t}-\right.$ mean $\left.\left(P M A_{i r t}\right)\right)$. The coefficient of main interest is $\alpha_{2}$, while controlling for heterogeneity, $\alpha_{5}$. Finally, we account for firms' self selection into early and late stage R\&D cooperations using the inverse Mill's ratios $C T_{1}$ and $C T_{0}$. They account for the fact that unobserved firm-level attributes might strengthen firms positions in the technology and product markets, and also increase the likelihood to form R\&D cooperation. Finally, we control for time-specific fixed effects using time dummies (Time).

An equivalent equation is estimated to evaluate the impact of early and late stage $\mathrm{R} \& \mathrm{D}$ cooperations $\left(d_{i r t}^{Y}\right)$ on the technology market $\left(T M A_{i r t+j}\right)$ :

$$
\begin{aligned}
& T M A_{i r t+j}=\beta_{1}+\beta_{2} d_{i r t}^{Y}+\beta_{3} P M A_{i r t}+\beta_{4} T M A_{i r t}+\beta_{5} d_{i r t}^{Y} *\left(T M A_{i r t}-\operatorname{mean}\left(T M A_{i r t}\right)\right) \\
& +\beta_{6} C T_{i t}^{1}+\beta_{7} C T_{i t}^{0}+\sum_{i=8}^{27} \beta_{t} T i m e_{i r t}+\xi_{i r t} .
\end{aligned}
$$

The specification follows equation 2 and the coefficient of main interest is $\beta_{2}$, while controlling for heterogeneity, $\beta_{5}$.

\section{Empirical results}

We first report the results from estimating the selection equation 1 into early/late stage R\&D cooperations, and then turn to the impact of early/late stage R\&D cooperations on the product market (equation 2) and the therapeutic market (equation 3). 


\subsection{Selection into early/late stage $R \& D$ cooperations}

We estimate the selection equation 1 using a probit model. Based on the estimation results, we test for the presence of unobserved heterogeneity by estimating $\rho=\frac{\sigma_{c}^{2}}{\left(1+\sigma_{c}^{2}\right)}$, where $\rho$ is the proportion of total variance contributed by the panel-level variance component. Our test returns significant estimates of $\rho$ of 0.342 and 0.388 with $p$ values of 0.00 , which confirms the presence of unobserved heterogeneity. Following Wooldrige (2002), we control for unobserved heterogeneity by including additional time-invariant firm-specific regressors $[\operatorname{mean}(T M A)]$ and $[$ mean $(P M A)]$ in our model specification and apply a probit estimation procedure.

The estimation results are shown in Table 6. Columns 2 and 3 report the marginal effects for signing early and late stage R\&D cooperations, respectively. As shown in column 2, a 10 percent decrease in the therapeutic market activity $(T M A)$ significantly increases the likelihood of forming early stage $R \& D$ cooperations by 5 percent. Hence, early stage R\&D cooperations are more relevant among firms which are less active in therapeutic areas. Research projects at the early stages, which involve the invention of new drug molecules, are costly and firms face impediments in financing those projects. Early stage R\&D cooperations are formed among more financially constrained firms and allow firms to share costs and to overcome financial constraints. This finding is consistent with the results found in previous studies.

Interestingly, a stronger presence in the product market $(P M A)$ has an insignificant impact on forming early stage cooperations. One explanation is that active firms in the product market do not rely on sharing $R \& D$ expenses. This explanation is supported by the fact that active firms in the product market benefit from higher revenues earned from their marketed drugs. Hence, they are less constrained in performing their basic research projects. Another explanation is that active firms are more hesitant to reveal information on their early stage research projects to competitors. Therefore, more established firms in the product market do not have an incentive to form R\&D cooperations at the early stage. 
Turning to firms' experience of engaging into early stage R\&D cooperations $\left(E X P^{\text {Early }}\right)$, our results show that one further past engagement in early stage R\&D cooperation increases the probability of engaging into an early stage R\&D cooperation by 5 percent. More experience in joining early stage $R \& D$ cooperation lowers firms' transaction and contracting costs due to improved organizational and management skills. Note that experience in late stage $\mathrm{R} \& \mathrm{D}$ cooperation lowers the probability of engaging into cooperation at the early stage. This result indicates that transaction costs are specific to the type of cooperation and also supports the relevance to distinguish between cooperation formed at the early and late stages. Moreover, this result also confirms that experience has a direct impact on forming R\&D cooperation, a result that supports our identification argument.

Firms' presence in different technology and product markets (Tech and Product) turns out to have an insignificant impact on forming early stage cooperations. Firms are not able to gain higher benefits via spillovers and transferring their knowledge from one therapeutic area to other therapeutic areas. Hence, knowledge is highly area-specific and not easily transferable. This result confirms that therapeutic area-specific expertise is important for the types of $\mathrm{R} \& \mathrm{D}$ cooperations.

Finally, firm-level heterogeneity in the technology market [mean $(T M A)]$ explains firms' choice to engage in early stage R\&D cooperations. Omitting the firm-level heterogeneity would result in an overestimated impact of technology market level of activity on forming early stage cooperations.

Turning to the estimation results for late stage R\&D cooperations (see Table 6, Column 3 ), it is interesting to note that a 10 percent increase in a firm's therapeutic market level of activity $(T M A)$ increases the likelihood of forming late stage $\mathrm{R} \& \mathrm{D}$ cooperations by 9.2 percent. Firms search for partners with similar research agendas and a strong experience in applied drug testing to increase the success probability of launching new drugs. Hence, more research active firms select themselves into late stage $R \& D$ cooperations. This result stands in contrast to early stage R\&D cooperations, which are rather formed among less research active firms. In general, the results show that self-selection into early and late 
stage cooperations occurs depending on their level of activity in the technological market.

Moreover, a strong product market presence $(P M A)$ has a positive impact on forming late stage cooperations. An increase in a firm's product market level of activity $(P M A)$ by 10 percent increases the likelihood of forming a late stage R\&D cooperation by 23 percent. The tendency to cooperate with close product market competitors at the final stages of the research process emphasizes the fact that human subject management, and drug safety testing are important drivers for participating in late stage R\&D cooperations. Moreover, since a drug becomes more likely to be launched on the market once it passed the final stages of the research process, firms are more effective in pooling their R\&D efforts, as well as re-optimizing their drug development portfolios to avoid closely related substitute drug production. Hence, stronger product market competitors self-select into late stage cooperations once the drug development process approaches the final stages.

The experience in late stage cooperations increases the likelihood of engaging in further late stage cooperations. This result again shows that transaction costs are rather specific to the type of $\mathrm{R} \& \mathrm{D}$ cooperations. It also emphasizes the fact that the objectives and requirements change throughout the $R \& D$ process and firms specialize in participating in early or late stage cooperations. The estimates for the technology market (Tech) and product market (Product) portfolios carry a positively and negatively significant estimate, respectively. Firms, diversified in technology markets, benefit from late stage cooperations managing large number of late stage clinical trials and research projects. Firms, diversified in product markets, have more in-house expertise and need less external knowledge. Finally, the firm-level heterogeneity, $[\operatorname{mean}(T M A)]$ and $[\operatorname{mean}(P M A)]$, resembles the previous finding that firms' presence in the technology and product market has a significant impact on explaining late stage cooperations. Hence, firm-specific factors associated with both technology and product markets are important in explaining the engagement into late stage $\mathrm{R} \& \mathrm{D}$ cooperations.

To summarize, the probit results provide evidence that firms select themselves into early and late stage cooperations, depending on their presence in the technological and 
product markets. Early stage R\&D cooperations are used as an instrument for less research active firms to overcome financial impediments. Late stage R\&D cooperations are performed among active firms in therapeutic and product markets. Moreover, the results show that previous experience in engaging into specific types of $R \& D$ cooperations has a significant impact, confirming our identification argument.

\subsection{Impact of early/late stage cooperations on technology and}

\section{product markets}

In this section, we report on the impact of early/late stage $R \& D$ cooperations on the technology and product market. We apply an estimation procedure which accounts for selection on observables and unobservables and also accounts for post selection heterogeneity. Using the estimates from the probit selection equation (1), we construct the selection terms for the early and late stage $R \& D$ cooperations and estimate the impact on the product and technology market according to equations (2) and (3), respectively ${ }^{25}$. Note, the error terms in the outcome equations and firms' positions in the markets might be correlated, causing a potential endogeneity problem. We therefore use different lags of the technology and product market variables as instruments, which is common practice in panel data estimations.

Table 7 shows the estimation results of early and late stage R\&D cooperations, also referred to as the average treatment effect on the treated (ATET). The upper left panel of Table 7 shows the impact of early stage cooperations on the technology market. Moving along the columns shows how the impact evolves over time. The results show that early stage cooperations increase the technology market level of activity. Accounting for the fact that a firm participates on average in 5.3 early stage $R \& D$ projects ${ }^{26}$, we can predict that early stage $R \& D$ cooperations increase the level of activity in the therapeutic market by $21 \%(30 \%)$, one (two) years after the cooperation formation. The results indicate that

\footnotetext{
${ }^{25}$ We estimate the model accounting for an impact of one and two years after cooperations have been formed. Due to data constraints, we are not able to evaluate longer time horizons.

${ }^{26}$ See Table 5.
} 
firms benefit from knowledge spillovers and scope economies, which encourage firms to initiate further individual projects over time. Considering the previous result that less research active firms engage in early stage cooperations, which also help firms overcome their financial constraints, we can conclude that economies of scope from early stage R\&D cooperations helps firm to successfully overcome their financial constraints ${ }^{27}$.

The upper right panel of Table 7 shows the impact of early stage R\&D cooperations on the product markets, see Column 5. The results show that early stage R\&D cooperations increase firms' level of activity in the product market by $22 \%$ (34\%), one (two) years after formation. It is important to note that early stage $R \& D$ cooperations further increase firms' level of activity over time. Hence, the economies of scope from knowledge base created in early stage $R \& D$ cooperations have long lasting synergy effects and allow firms to increase the number of drugs offered on the market.

It is worth comparing the impact of economies of scope, created in early stage R\&D cooperations, on the therapeutic market activity with the impact on the product market activity, see Table 7, Columns 3 and 5. The short-run impact (one year after the cooperations) resulted in a comparable increase of around $22 \%$ in firms' level of activity in the therapeutic and product market area. The long-run impact (two years after the cooperations) on the number of drugs offered on the market increased by $4 \%$ more than the $R \& D$ projects. At first glance, this seems to be surprising as research projects result in new drugs launched on the market. Therefore, we would rather expect a lower impact on drugs marketed than on new research activity. This argument is even more pronounced if we take into consideration that some research activities may also become obsolete due to a high degree of uncertainty in R\&D. Hence, the numbers clearly illustrate two effects: first, early stage cooperations enable firms to overcome financial constraints and the economies of scope created from R\&D cooperations increase their research activities. Second, the number of drugs increases significantly in the long run and even overturns the increase in research projects. This result illustrates that firms are able to diffuse their newly gained

\footnotetext{
${ }^{27}$ Remember that Table 6 , Column 2 shows a negative impact of $T M A$ on the likelihood of forming early stage cooperations.
} 
knowledge base towards their individual projects which increases the number of drugs launched on the market. This shows that the economies of scope generated from public goods nature of the knowledge base benefit early stage $R \& D$ cooperation signing firms.

The lower left panel of Table 7 (Column 3) shows that late stage cooperations increase the therapeutic market level of activity by $12 \%$ in the short-run ${ }^{28}$. This impact is lower than in early stage cooperations, emphasizing the notion that synergy effects are lower in late stage cooperations than in early stage cooperations. This seems plausible as economies of scope generated from knowledge spillovers are higher at the early basic research stages than in the later stages in which drugs are mostly in clinical trials. Note that the short-run gains are not sustainable in the long run.

The lower right panel of Table 7 (Column 5) shows the impact of late stage cooperations on the product market. Focusing on the short-run effect, firms are able to increase their number of drugs launched on the market by $6 \%$ one year after a late stage cooperation has been formed. This impact is significantly smaller than the short-run effect of early stage R\&D cooperations on product markets, which confirms the fact that economies of scope created from knowledge spillover is more prominent and dominant at the early stages of the research process rather than at the late stages. These results support Henderson and Cockburn (1996)'s assumption that economies of scope generated from public goods nature of the knowledge base is more prominent during the early stages of the drug development. Very surprisingly, the short-run impact of late stage cooperations on the therapeutic market is $12 \%$, while the same impact on the product market is only $6 \%$. This finding has two alternative explanations: either many research projects that were initiated after the $R \& D$ cooperations become unsuccessful, or late stage $R \& D$ cooperations provide an opportunity for firms to coordinate their drug development portfolios as to avoid wasteful duplication and to avoid highly substitutable drugs being launched on the market. To summarize, in the short run, the number of R\&D projects drastically increases while the number of new drugs offered on the product market only slightly increases. Most

\footnotetext{
${ }^{28}$ This number is evaluated at the average number of late stage projects (6.89 late stage R\&D projects) that firms are involved in.
} 
impressive is the finding that the long-run impact of late stage R\&D cooperations on the product market is negative, i.e., the number of drugs decreases by $49 \%$ two years after a late stage $R \& D$ cooperation has been formed. Part of the reduction is explained by the non-significant impact of late stage $\mathrm{R} \& \mathrm{D}$ cooperations on the therapeutic market. However, this would only explain a non-increase in the number of drugs. The drastic reduction is rather explained by the fact that $R \& D$ cooperations represent an opportunity for firms to re-optimize their drug portfolios and to avoid close substitutes being offered on the market. Recall, that late stage cooperations increase firms R\&D activity but reduce their product market activity. Moreover, this explanation is consistent with the previous finding that active firms in research and production engage in late stage $R \& D$ cooperations (see Table 6), and active firms in the product market are more likely to cannibalize each other's sales by introducing similar drugs into the market. Hence, the gain to re-optimize drug portfolios and avoiding the introduction of closely related drugs is higher for those firms.

We now turn to discuss the counterfactual impact on the therapeutic and product market level of activity, if firms which did not engage in early/late stage R\&D would have formed one of those cooperations, see Table $8^{29}$. The upper panel of Table 8, Column 3, shows that early stage cooperations do not significantly impact firms' technology market level of activity. This result is plausible as those firms did not self-select themselves into early stage R\&D cooperations. Consequently, non-selected firms would not find the same benefit as those who self-selected themselves into early R\&D cooperations, i.e., overcoming financial constraints. Consequently, firms would have not increased their research activity. Interesting is the following result: if noncooperating firms would have selected themselves into early stage cooperations, product market level of activity would have increased by $32 \%$ one year later. This result emphasizes the fact that the product market gains and efficiency gains in clinical trials are not constrained to self-selected firms, but could have been achieved by other firms as well.

Finally, the lower panel of Table 8 shows that late stage cooperations increase tech-

\footnotetext{
${ }^{29}$ Also commonly referred to as the treatment effect on the nontreated (ATENT).
} 
nology (product) market level of activity by $12 \%$ (8\%) in the short run. This positive effect, however, is not sustainable in the long run and disappears. Comparing this result to the sample of firms that self-selected themselves into late stage cooperations (see lower panel of Table 7, Column 5), we realize that the impact on product market is higher (see Table 8). Hence, firms which did not self-select into late stage R\&D cooperations would have not reduced the number of drugs. Firms' benefit in re-optimizing their drug portfolios is also supported by the previous finding that more active firms in research and production engage in late stage $R \& D$ cooperations, and these firms benefit the most from coordinating and re-optimizing drug portfolios. Finally, the results for the average treatment effects of early and late stage R\&D cooperations, as shown in Table 9, resemble the results in Tables 7 and 8.

Robustness checks The technology and product market level of activity variables, TMA and PMA, represent the most relevant variables in our study. Since the results might be sensitive to the specific variable definition, we apply robustness checks with respect to different definitions of those variables. Hence, we weighted TMA and PMA by the Herfindahl index of the technology market and the product market areas. This definition accounts for the level of activity in the technology and product markets relative to other technology and product markets. $T M A$ is defined as:

$$
\begin{aligned}
& T M S_{i r t}=\frac{\widetilde{z}_{i r t}}{\sum_{i=1}^{N} \widetilde{z}_{i r t}^{2}} . \\
& T M A_{i r t}=T M S_{i r t}+\sum_{s=1}^{t-1}(1-\delta)^{s} T M S_{i r t} .
\end{aligned}
$$

And $P M A$ is defined as:

$$
P M S_{i r t}=\frac{\widetilde{p}_{i r t}}{\sum_{i=1}^{N} \widetilde{p}_{i r t}^{2}} .
$$




$$
P M A_{\text {irt }}=P M S_{\text {irt }}+\sum_{s=1}^{t-1}(1-\delta)^{s} P M S_{\text {irt }} .
$$

The results for the first stage probit and the heterogeneous treatment effect do not change significantly ${ }^{30}$. We run the probit without the portfolio diversification variables (Tech and Product). All coefficient estimates obtained are of same sign and significance level, except $P M A$ for the prediction of the likelihood of signing early stage cooperations. The sign was negative at the $10 \%$ significance level. Additionally, we run the model with time trend instead of time dummies without any significant change in the result. Finally, we also apply an alternative estimation method, i.e., a propensity score estimator to check for the associated conditional independence assumption. Given the data availability, we conclude with three stratas in our propensity estimation method, and find that the basic results are unchanged.

\section{Conclusion}

This study analyzes the impact of $R \& D$ cooperations formed at different stages on technology and product market competition in the pharmaceutical industry. Using a rich dataset on firms' activities in therapeutic and disease areas over time, we estimate a heterogeneous treatment effect model and account for firms selecting themselves into early and late stage $R \& D$ cooperations (pre-treatment heterogeneity). Moreover, we explicitly allow firms having a specific impact on the therapeutic and product market after having selected themselves into specific types of R\&D cooperations (post-treatment heterogeneity).

We find that early stage R\&D cooperations are formed among less research-active companies, which supports previous findings that less research active firms use early stage R\&D cooperations as an instrument to overcome financial constraints. On the contrary, late stage $\mathrm{R} \& \mathrm{D}$ cooperations are formed among more research-active and productionoriented firms. The result reflects that product market competitors avoid disclosing their

\footnotetext{
${ }^{30}$ The results are available from the authors upon request.
} 
research pipeline to their competitors at the early stages. At the later stages, however, their incentive to form $\mathrm{R} \& \mathrm{D}$ cooperations with close product market competitors increases.

Our results show that early stage R\&D cooperations increase firms' level of activity in the therapeutic and product markets. This emphasizes that economies of scope are prevalent during the early stages of the drug development. Most interestingly, we find that late stage $R \& D$ cooperations significantly reduce the number of drugs launched on the market, even though they increased firms' activity in the technology markets. This result highlights the fact that firms re-optimize their drug development portfolio to avoid wasteful duplication and cannibalizing the sales of the jointly developed drugs in R\&D cooperations.

To conclude, our study suggests that antitrust authorities should pay special attention to late stage cooperations, as those have the potential to lower the number of drugs offered on the market, causing a potential harm to product market competition and consumer welfare. Even though, we believe that this study provides an important insight into different types of R\&D cooperations and their ultimate impact on product variety, we also would like to emphasize that this study is one of the first studies in this area, and further research is warranted to derive stronger policy statements. For example, it would be interesting to analyze to what extent different types of $R \& D$ cooperations impact the prices of the developed drugs. These questions, however, are beyond the scope of our study and our data availability. 


\section{References}

Angrist, J. and A. Krueger, 1999, "Empirical strategies in labor economics," Handbook of Labor Economics, in: O. Ashenfelter and D. Card (ed.), edition 1, 3(23), pp. 1277-1366, Elsevier.

Arora, A., A. Gambardella, L. Magazzini and F. Pammolli, 2009, "A Breath of Fresh Air? Firm Type, Scale, Scope, and Selection Effects in Drug Development," Management Science, INFORMS, 55(10), pp. 1638-1653.

Brand, J.E. and J.S. Thomas, 2012, "Casual Effect Heterogenity," http://papers.ccpr.ucla.edu/papers/PWP-CCPR-2011-012/PWP-CCPR-2011-012.pdf.

Brand J.E. and Y. Xie, 2010, "Who benefits most from college? Evidence for negative selection in heterogeneous economic returns to higher education," American Sociological Review, 75, pp. 273-302.

Cabral, L., 2000, "R\&D cooperations and product market competition," International Journal of Industrial Organization, 18, pp. 10331047.

Cassiman, B. and R. Veugelers, 2002, "Spillovers and R\&D Cooperation: Some Evidence from Belgium," American Economic Review, 92(4), pp.1169-1184.

Cerulli G., 2012, “ivtreatreg: a new STATA routine for estimating binary treatment models with heterogeneous response to treatment under observable and unobservable selection," CNR-Ceris Working Papers, No. 03/12.

D'Aspremont, C. and A. Jacquemin, 1988, "Cooperative and Noncooperative R\&D in Duopoly with Spillovers," American Economic Review, 78, pp. 1133-1137.

Danzon, P., S. Nicholson and N.S. Pereira, 2005, "Productivity in pharmaceuticalbiotechnology R\&D: the role of experience and alliances," Journal of Health Economics, 24(2), pp.31739. 
Dehejia, H.R. and S. Wahba, 2002, "Propensity score-matching methods for nonexperimental causal studies," The Review of Economics and Statistics, MIT Press, 84(1), pp. 151-161.

DiMasi, J.A., R.W. Hansen, H.G. Grabowski and L. Lasagna, 1991, "Cost of innovation in the pharmaceutical industry," Journal of Health Economics, 10, pp. 107-142.

DiMasi, J.A., R.W. Hansen and H.G. Grabowski, 2003, "The price of innovation: new estimates of drug development costs," Journal of Health Economics, 22, pp. 151-185

DiMasi, J.A., L. Feldman, A. Seckler and A. Wilson, 2010, "Trends in risks associated with new drug development: success rates for investigational drugs," Clinical Pharmacology \& Therapeutics, 87, pp. 272277.

Erkal, N. and D. Minehart, 2008, "Optimal Sharing Strategies in Dynamic Games of Research and Development," Available at SSRN: http://ssrn.com/abstract=997336.

Goeree, M.S. and E.A. Helland, 2010, "Do Research Joint Ventures Serve a Collusive Function?," http://www.econ.uzh.ch/faculty/mgoeree/research/rjvmay18.pdf.

Griliches, Z. and J. Mairesse, 1984, "Productivity and R\&D at the firm level, in Z. Griliches (ed.), R\&D, Patents, and Productivity," The University of Chicago Press and NBER: Chicago.

Griliches, Z. 1977, "Estimating theReturns to Schooling:Some Econometric Problems," Econometrica, 45, pp. 122.

Grabowski G. H. and K. Margaret, 2012, "Mergers, Accquisitions, and Alliances, in The Oxford Handbook of The Economics of the Biopharmaceutical Industry, " edited by Patricia M. Danzon and Sean Nicholson, pp. 552-577, Oxford Press.

Grossman, G.M. and C. Shapiro, 1986, "Optimal Dynamic R\&D Programs," RAND Journal of Economics, The RAND Corporation, 17(4), pp. 581-593. 
Grossman, G.M. and C. Shapiro, 1987, "Dynamic R\&D Competition," Economic Journal, $97(386)$, pp. 372-87.

Gugler K. and R. Siebert, 2007, "Market Power versus Efficiency Effects of Mergers and Research Joint Ventures: Evidence from the Semiconductor Industry," Review of Economics and Statistics, 89(4), pp. 645-659.

Hall, B.H., 1993, "The stock market's valuation of R\&D investment during the 1980's," American Economic Review, 83, pp. 259-264.

Heckman J., S. Urzua and E. Vytlacil, 2006, "Understanding Instrumental Variables in Models with Essential Heterogeneity," The Review of Economics and Statistics, 88, pp. 389-432.

Henderson, R. and I. Cockburn, 1996, "Scale, Scope, and Spillovers: The Determinants of Research Productivity in Drug Discovery, " RAND Journal of Economics, 27(1), pp. $32-59$.

Henderson, R and I. Cockburn, 2001, "Scale and Scope in Drug Development: Unpacking the Advantages of Size in Pharmaceutical Research," Journal of Health Economics, 20(6), pp. 1033-1057.

Higgins, M.J. and D. Rodriguez, 2006, "The Outsourcing of R\&D through Acquisition in the Pharmaceutical Industry," Journal of Financial Economics, 80.

Holland, P., 1986, "Statistics and Causal Inference," Journal of the American Statistical Association, 81, pp. 945-970.

Irwin, D. and P. Klenow, 1996, "High Tech R\&D Subsidies: Estimating the effects of SEMATECH," Journal of International Economics, 40,(3-4), pp. 323-344.

Jorde, T. and J. T. David, 1990, "Innovation and Cooperation: Implications for Competition and Antitrust," Journal of Economic Perspectives, 4(3), pp. 75-96. 
Kamien, M., E. Muller and I. Zang, 1992, "Research Joint Ventures and R\&D Cartels," American Economic Review, 82, (5), pp. 1293-1306.

Katz, L.M., 1986, "An Analysis of Cooperative Research and Development," The RAND Journal of Economics, 17(4), pp. 527-543.

Lancaster, K., 1979, "Variety, Equity and Efficiency," New York, Columbia University.

Lerner, J., and A. Tsai, 2000, "Do Equity Financing Cycles Matter? Evidence From Biotechnology Alliances, ” Journal of Financial Economics, 67,(3), pp. 411446.

Lerner, J. and R.P. Merges, 1998, "The control of technology alliances: an empirical analysis of the biotechnology industry," Journal of Industrial Economics, 46, pp. $125-156$.

Martin, S., 1995, "R\&D joint ventures and tacit product market collusion," European Journal of Political Economy, 11, pp. 73341.

Morgan, S. and W. Christopher, 2007 "Counterfactuals and Causal Inference: Methods and Principles for Social Research," Cambridge, UK: Cambridge University Press.

Nesta, L. and P.P. Saviotti, 2005, "Coherence of the knowledge base and the firms' innovation performance: Evidence from the U.S. Pharmaceutical industry," Journal of Industrial Economics, Wiley Blackwell, 53(1), pp. 123-142.

Nicholson, S., P.M. Danzon, and M. Jeffrey, 2003, "Biotech-pharmaceutical alliances as a signal of asset and firm quality, " Journal of Business.

Ornaghi, C., 2009, "Mergers and innovation in big pharma," International Journal of Industrial Organization, 27, pp. 7079.

Oxley, J.E. and R.C. Sampson, 2004, "The scope and governance of international R\&D alliances," Strategic Management Journal, 25, pp. 723-750.

Pais, J., 2011, "Socioeconomic background and racial earnings inequality: A propensity score analysis," Social Science Research, 40, pp. 37-49. 
Powell, W.W. and P.Brantley, 1992, "Competitive cooperation in biotechnology: learning through networks? In: Nohria, N., Eccles, R.G. (Eds.), Network and Organizations: Structure, Form and Action," Harvard Business School Press, Boston, pp. 366394

Powell, W.W., K.W. Koput, L. Smith-Doerr and J. Owen-Smith, 1999, "Network position and firm performance: organizational returns to cooperation in the biotechnology industry, " In: Andrews, S., Knoke, D. (Eds.), Networks in and Around Organizations. JAI Press, Greenich, CT.

Roeller, L.H., R. Siebert and M. Tombak, 2007, "Why Firms Form (or don't Form) RJVs," Economic Journal, 117(522), pp. 1122-1144.

Roeller, L.H., D. Tomaso and J. Seldeslachts, 2013, "Collusion Through Joint R\&D: An Empirical Assessment," The Review of Economics and Statistics.

Saami Z., 2006, "Suppression Of Innovation Or Collaborative Efficiencies?: An Antitrust Analysis Of A Research \& Development Collaboration That Led To The Shelving Of A Promising Drug," 5 J. Marshall Rev. Intell. Prop. L. 348.

Salop, S.C., 1979, "Monopolistic Competition with Outside Goods," Bell Journal of Economics, 10, pp. 141-156.

Sakakibara, M., 2002, "Formation of R\&D Consortia:Industry and Company Effects," Strategic Management Journal, 23(11), pp. 1033-1050.

Shapiro C. and D. R. Willig, 1990, "On the Antitrust Treatment of Production Joint Ventures," Journal of Economic Perspectives.

Siebert, R. and G. V. Graevenitz, 2010, "Jostling for Advantage or Not: Choosing Between Patent Portfolio Races and Ex Ante Licensing," Journal of Economic Behavior \& Organization, 73, pp. 225-245. 
Siebert, R. and G. V. Graevenitz, 2012, "Are Licensing Agreements Appropriate Instruments to Cut Through the Patent Thicket?," http://www.law.northwestern.edu/searlecenter/papers/Siebert_Licensing_Agreements.pdf

Spence, M., 1984, "Cost Reduction, Competition, and Industry Performance," Econometrica, Econometric Society, 52(1), pp. 101-21.

Suetens S., 2008, "Does R\&D cooperation facilitate price collusion? An experiment," Journal of Economic Behavior and Organization, 66, pp. 822-836.

Wooldridge, J. M., 2002, "Econometric analysis of cross section and panel data," MIT Press, Cambridge, Mass. 


\section{Appendix}

\subsection{The basic framework}

We introduce the theoretical underlying framework to estimate the impact of early and late stage $R \& D$ cooperations on technology and product market level of activity. We begin with firms' decisions to join an early stage R\&D cooperation, or not ${ }^{31}$.

Let $V_{i r t}^{*}$ be the present value of firm $i=1, \ldots, N$ in market $r$ in period $t^{32}$ :

$$
V_{i r t}^{*}=\widetilde{\alpha} P M A_{i r t}+\widetilde{\beta} T M A_{i r t}+\epsilon_{i r t},
$$

where $P M A_{\text {irt }}$ and $T M A_{\text {irt }}$ refer to the product and technology market level of activity, respectively, and $\epsilon_{\text {irt }}$ is a i.i.d. normally distributed error term with mean zero. The present value of a firm that joined an early stage $R \& D$ cooperation (indexed by superscript 1), is given by:

$$
V_{i r t}^{1 *}=\alpha_{1} P M A_{i r t}^{1}+\beta_{1} T M A_{i r t}^{1}+\epsilon_{i r t}^{1}
$$

The present value of a noncooperating firm (indexed by superscript 0 ), is:

$$
V_{i r t}^{0 *}=\alpha_{0} P M A_{i r t}^{0}+\beta_{0} T M A_{i r t}^{0}+\epsilon_{i r t}^{0} .
$$

We can infer that a firm joins an early stage $R \& D$ cooperation, if $V_{i r t}^{1 *}>V_{i r t}^{0 *}$. Note, that we don't observe $V_{\text {irt }}^{1 *}$ or $V_{\text {irt }}^{0 *}$, but we observe if a firm forms an early or late stage R\&D cooperation. Hence, a firm's cooperation decision is based on the following equation:

$$
V_{i r t}^{*}=V_{i r t}^{1 *}-V_{i r t}^{0 *}=\alpha\left(P M A_{i r t}^{1}-P M A_{i r t}^{0}\right)+\beta\left(T M A_{i r t}^{1}-T M A_{i r t}^{0}\right)+\epsilon_{i r t}^{*}
$$

where $\epsilon_{i r t}^{*}=\epsilon_{i r t}^{1}-\epsilon_{i r t}^{0}$. As shown in the equation, firms make their decisions to form a $\mathrm{R} \& \mathrm{D}$ cooperation based on their impact in the technology and product markets. Ideally,

\footnotetext{
${ }^{31}$ The same rationale applies to a firm's decision to engage in a late stage R\&D cooperation. Remember, that the two types of cooperations are characterized by different objectives and therefore are not considered to be substitutes for one another. Moreover, as argued above, it is reasonable to assume that the decisions to form early and late stage cooperations are independent.

${ }^{32}$ Note, that the decision to form an early or late stage $R \& D$ cooperation is based on the value of an individual firm. In our context, this is a more reasonable approach than considering the sum of firm values in a firm-pair, as the latter would implicitly assume that firms cooperated in the R\&D as well as the product market, which is unlawful.
} 
we would be interested in estimating the hypothetical heterogeneous treatment effect for firm $i$ on the product market:

$$
\alpha_{i}=P M A_{i r t}^{1}-P M A_{i r t}^{0},
$$

and on the technology market:

$$
\beta_{i}=T M A_{i r t}^{1}-T M A_{i r t}^{0} .
$$

However, we observe at most only one of the two outcomes, $P M A_{i}^{1}$ or $P M A_{i}^{0}$, but not both, i.e., the fundamental problem of causal inference, see Holland (1986) ${ }^{33}$. Hence, identifying a direct treatment effect is beset with a missing data problem and deriving causal inferences is not feasible at the individual level.

We proceed with performing a comparison at the group level, and decompose the $P M A^{1}$ into its mean $\mu^{1}(X)$ given regressors $X$, and its deviation from the mean $u^{1}$.

$$
P M A^{1}=\mu^{1}(X)+u^{1} .
$$

A similar decomposition is applied to $P M A^{0}$ :

$$
P M A^{0}=\mu^{0}(X)+u^{0} .
$$

We assign a treatment variable denoted by the binary variable $d_{i}^{Y}$, Y=Early (Late), which takes on a value of one if firm $i$ joined an early (late) stage R\&D cooperation, respectively. Since firms are observed only if $d_{i}^{Y}=1$ or $d_{i}^{Y}=0$, we use a switching regression framework, and obtain for the observed outcome,

$$
P M A=d^{Y} P M A^{1}+\left(1-d^{Y}\right) P M A^{0} .
$$

Substituting the above equations, yields

$$
P M A=P M A^{0}+d^{Y}\left(P M A^{1}-P M A^{0}\right)=\mu^{0}+d^{Y}\left[\mu^{1}(X)-\mu^{0}(X)+u^{1}-u^{0}\right]+u^{0},
$$

\footnotetext{
${ }^{33}$ The following outline refers to the product market level of activity, $P M A$. Note, that they also apply to the technology market level of activity $T M A$.
} 
where the second term expresses the benefit of participation. The first component $\mu^{1}(X)-$ $\mu^{0}(X)$ measures the average gain to a firm described by characteristics $X$. The second component $u^{1}-u^{0}$ is the individual-specific benefit. Replacing for $\mu^{0}=g_{0}(X)+e_{0}$ and $\mu^{1}=g_{1}(X)+e_{1}$ and using regression notation, we get

$$
P M A_{i}=\gamma X_{i}+\alpha d_{i}^{Y}+g_{0}\left(X_{i}\right)+d_{i}^{Y}\left(X_{i}-\mu^{x}\right) b+\epsilon_{i}
$$

where $\gamma X=\mu^{0}(X)$, and $\alpha=\left(P M A^{1}-P M A^{0}\right)=\mu^{1}(X)-\mu^{0}(X)+e^{1}-e^{0}$ and $\epsilon=e^{0}$. The parameter $\gamma$ is a regression coefficient measuring the changes in $P M A$ associated with the changes in the firm characteristics $X$. The coefficient $\alpha$ represents the change in $P M A$ associated with the $\mathrm{R} \& \mathrm{D}$ cooperation. Even though our goal is to estimate a heterogeneous treatment, $\alpha_{i}$, for simplicity, we briefly consider a homogeneous treatment effect, i.e., $\alpha=P M A^{1}-P M A^{0}$ is the same for all firms. In this restricted case, a least square regression (a mean difference between cooperating and noncooperating firms) is subject to a potential selection bias or pre-treatment heterogeneity bias. This bias is due to a non-zero correlation between $d_{i}^{Y}$ and $\epsilon_{i}$, see also Griliches (1977). It is reasonable to assume that stronger positions in the technology and/or product markets will directly affect future technology and product market positions, as well as participation in R\&D cooperations. Therefore, we have to take into account that firms self-select themselves into early or late stage R\&D cooperations dependent on potential outcomes in the therapeutic and product market. Regarding the self-selection problem, we also need to account for the fact that firms are characterized by different attributes, some of which are unobserved. Hence, conditional on observed covariates there are unobserved factors that are associated with the participation and potential outcomes on the therapeutic and product markets ${ }^{34}$. Since the ignorability assumption ignores heterogeneity due to unobserved variables, we apply an identification strategy based on instrumental variables.

Finally, even after correcting for the selection bias or pre-treatment heterogeneity bias,

\footnotetext{
${ }^{34}$ This implies that we cannot keep the conditional independence assumption or the ignorability assumption, which states that outcomes are uncorrelated with treatment status(or engaging into $R \& D$ cooperations), conditional on observed covariates. For applications based on the conditional independence assumption using propensity score estimation methods, see e.g., Brand and Xie (2010), Brand and Thomas (2012) and Pais (2011)
} 
we have to be aware of a potential treatment heterogeneity effect bias, which is based on $\operatorname{Cov}(\alpha, d) \neq 0$, see also Heckman et al. (2006). This is a crucial concern in our application as firms are sorting themselves on the gain to improve their positions in the technology and product markets. Our study relaxes the homogeneity assumption and allows the responses of the treatment $\alpha_{i}=P M A_{i}^{1}-P M A_{i}^{0}$ to vary across firms (heterogeneity) applying the heterogeneous treatment effects model, as will be further discussed below. 
Table 1: Drug development stages

\begin{tabular}{ll}
\hline \hline Stage & Description \\
\hline Discovery & Target identification, biochemical mechanism. \\
Formulation & Identifying drug's stability. \\
Lead Molecule & Identifying the lead molecule for the development. \\
Preclinical & On animals to find out various parameters. \\
Phase I & Small-scale, identify tolerance, repeated-dose studies. \\
& Healthy volunteers. Initial single-dose, dose increase. \\
Phase II & Small-scale, preliminary efficacy on patients. \\
Phase III & Large-scale clinical trials, safety and efficacy \\
& Large scale patients, Preparation for NDA. \\
\hline
\end{tabular}

Table 1 presents different drug development stages in the pharmaceutical industry. Source: www.pacificbiolabs.com/drug_stages.asp 
Table 2: Total number of approved NDA

\begin{tabular}{cccc}
\hline \hline Year & Total drugs & Year & Total drugs \\
\hline 1993 & 70 & 2002 & 78 \\
1994 & 62 & 2003 & 72 \\
1995 & 82 & 2004 & 119 \\
1996 & 131 & 2005 & 80 \\
1997 & 121 & 2006 & 101 \\
1998 & 90 & 2007 & 78 \\
1999 & 83 & 2008 & 89 \\
2000 & 98 & 2009 & 90 \\
2001 & 66 & 2010 & 93 \\
& & 2011 & 59
\end{tabular}

Table 2 presents the total number of NDA approved by FDA. Dataset is provided by Biopharm Insight (approved drug database). 
Table 3: Number of alliances in different technological areas

\begin{tabular}{lc}
\hline \hline Technological area & Number of Alliances \\
\hline Cancer & 781 \\
Cardiovascular & 226 \\
Central Nervous System & 380 \\
Dermatology & 86 \\
Diagnostic/Delivery & 36 \\
Eye and Ear & 110 \\
Gastrointestinal & 205 \\
Genitourinary & 90 \\
HIV Infections & 60 \\
Hematological & 100 \\
Hormonal Systems & 256 \\
Immune System & 198 \\
Infectious Diseases & 404 \\
Miscellaneous & 328 \\
Musculoskeletal & 162 \\
Nephrology & 38 \\
Pain & 200 \\
Respiratory & 96 \\
\hline Total & 3,756 \\
\hline \hline Phases & 561 \\
\hline Discovery & 123 \\
Formulation/Lead Molecule & 1087 \\
Pre-Clinical & 538 \\
Phase I & 798 \\
Phase II & 575 \\
Phase III & 74 \\
Regulatory Filing &
\end{tabular}

Table 3 presents the number of alliances in different technological areas, as well as alliances by phases at the time of the deal. Dataset is provided by Biopharm Insight. 
Table 4: Descriptive statistics for all companies

\begin{tabular}{lccccc}
\hline \hline Variable & Observations & Mean & Std. Dev. & Min & Max \\
\hline \multicolumn{7}{c}{ Treatment variables } \\
\hline Early & 7320 & 0.2262 & 0.4184 & 0 & 1 \\
Late & 7320 & 0.2868 & 0.4523 & 0 & 1 \\
\hline \multicolumn{7}{c}{ Explanatory variables } \\
\hline TMA & 7320 & 0.6382 & 0.0338 & 0 & 8.37 \\
PMA & 7320 & 0.0650 & 0.0057 & 0 & 17 \\
Tech & 7320 & 0.7170 & 2.3068 & 0 & 18 \\
Product & 7320 & 0.3453 & 1.4038 & 0 & 14 \\
EXP $P^{\text {Early }}$ & 7320 & 2.2394 & 5.4591 & 0 & 49 \\
EXP & 7320 & 3.4284 & 8.1471 & 0 & 60 \\
\hline
\end{tabular}

Table 4 presents summary statistics using data from 1993 until 2011 for all the cooperation-signing companies. Dataset is provided by Biopharm Insight. $T M A_{\text {irt }}$ refers to the technology market level of activity and $P M A_{\text {irt }}$ refers to the product market level of activity.

Table 5: Descriptive statistics by early and late stage partners

\begin{tabular}{|c|c|c|c|c|c|c|c|c|}
\hline \multicolumn{5}{|c|}{ Early stage partners } & \multicolumn{4}{|c|}{ Late stage partners } \\
\hline Variable & Mean & Std. Dev. & Min & Max & Mean & Std. Dev. & Min & Max \\
\hline$T M A$ & 1.2951 & 0.0473 & 0 & 8.37 & 1.2005 & 0457 & 0 & 7.9853 \\
\hline$P M A$ & 1.1754 & 0.0078 & 0 & 15.00 & 1.324 & 0.0080 & 0 & 17.00 \\
\hline Tech & 1.3503 & 3.1817 & 0 & 18 & 1.2667 & 2.9699 & 0 & 18 \\
\hline Product & 0.5100 & 1.9284 & 0 & 14 & 0.4328 & 1.5416 & 0 & 14 \\
\hline$E X P^{\text {Early }}$ & 5.3405 & 7.7078 & 0 & 49 & 3.5142 & 6.2862 & 0 & 44 \\
\hline$E X P^{\text {Late }}$ & 6.2983 & 11.2530 & 0 & 60 & 6.8861 & 9.6734 & 0 & 60 \\
\hline
\end{tabular}

Table 5 presents summary statistics using data from 1993 until 2011 for for early and late stage cooperationsigning companies separately. Dataset is provided by Biopharm Insight. $T M A_{\text {irt }}$ refers to the technology market level of activity and $P M A_{\text {irt }}$ refers to the product market level of activity. 
Table 6: Decision to form early and late stage $R \& D$ cooperations

\begin{tabular}{lll}
\hline \hline & Dependent variable: & Dependent variable: \\
VARIABLES & Early stage cooperation & Late stage cooperation \\
\hline TMA $A_{t-1}$ & $-0.0045^{*}$ & $0.0092^{* * *}$ \\
& $(0.003)$ & $(0.002)$ \\
PMA $A_{t-1}$ & 0.0006 & $0.0228^{* *}$ \\
& $(0.015)$ & $(0.011)$ \\
EXP Pearly & $0.0479^{* * *}$ & $-0.0450^{* * *}$ \\
& $(0.003)$ & $(0.003)$ \\
EXP $P^{\text {late }}$ & $-0.0280^{* * *}$ & $0.0412^{* * *}$ \\
& $(0.002)$ & $(0.002)$ \\
Tech & -0.0039 & $0.0240^{* * *}$ \\
& $(0.005)$ & $(0.004)$ \\
Product & 0.0092 & $-0.0626^{* * *}$ \\
& $(0.009)$ & $(0.007)$ \\
mean $(T M A)$ & $0.0136^{* *}$ & $0.0043^{* *}$ \\
mean $($ PMA $)$ & $(0.006)$ & $(0.004)$ \\
Time dummies & $-0.0781^{*}$ & $0.1033^{* * *}$ \\
\hline Ybservations & 7,320 & $(0.031)$ \\
Loglikelihood & -1911 & Yes \\
\hline
\end{tabular}

Table 6 presents the marginal effects of probit estimation for equation 5. Dependent variables are the early/late stage $R \& D$ cooperations. Explanatory variables are the lagged technology market level of activity, lagged product market level of activity, early/late stage experience, diversification in technology and product markets, the time averages of the technology and product market, and time dummies. Potential endogeneity and unobserved heterogeneity are controlled. Standard errors are shown in the parenthesis. $* * *$ and ${ }^{* *}$ denote $99 \%$ and $95 \%$ level of confidence. 
Table 7: Average treatment effect on treated: impact of early/late stage R\&D cooperations on technology and product markets

\begin{tabular}{lllll}
\hline \hline \multicolumn{5}{c}{ Technological and product market level of activity (ATET(x)) } \\
\hline Early stage cooperation & $T M A_{t+1}$ & $\begin{array}{l}0.0383^{* *} \\
(0.148)\end{array}$ & $P M A_{t+1}$ & $0.0412^{*}$ \\
& & & $(0.026)$ \\
& $T M A_{t+2}$ & $\begin{array}{l}0.0553^{* *} \\
(0.032)\end{array}$ & $P M A_{t+2}$ & $0.0636^{* *}$ \\
& & & & $(0.087)$ \\
Late stage cooperation & $T M A_{t+1}$ & $0.0171^{* *}$ & $P M A_{t+1}$ & $0.0093^{*}$ \\
& & $(0.005)$ & & $(0.005)$ \\
& $T M A_{t+2}$ & 0.0155 & $P M A_{t+2}$ & $-0.0713^{* *}$ \\
& & $(0.015)$ & & $(0.044)$ \\
\hline
\end{tabular}

Table 7 presents the instrumental variable estimation results for the impact of early and late stage R\&D cooperations on treated firms' level of activity in the technological and product market, one and two periods after forming a R\&D cooperation. Number of previous early and late stage cooperations are used as an instrument. Standard errors are shown in the parenthesis. ${ }^{* * *},{ }^{* *}$ and ${ }^{*}$ denote $99 \%, 95 \%$ and $90 \%$ level of confidence.

Table 8: Average treatment effect on nontreated: impact of early/late stage R\&D cooperations on technology and product markets

\begin{tabular}{ccccc}
\hline \hline \multicolumn{5}{c}{ Technological and product market level of activity (ATENT(x)) } \\
\hline Early stage cooperation & $T M A_{t+1}$ & 0.0348 & $P M A_{t+1}$ & $0.0596^{*}$ \\
& & $(0.141)$ & & $(0.022)$ \\
& $T M A_{t+2}$ & 0.0652 & $P M A_{t+2}$ & 0.0369 \\
& & $(0.032)$ & & $(.039)$ \\
Late stage cooperation & $T M A_{t+1}$ & $0.0181^{*}$ & $P M A_{t+1}$ & $0.0112^{* *}$ \\
& & $(0.007)$ & & $(0.005)$ \\
& $T M A_{t+2}$ & 0.0162 & $P M A_{t+2}$ & -0.1163 \\
& & $(0.013)$ & & $(0.047)$ \\
\hline
\end{tabular}

Table 8 presents the instrumental variable estimation results for the impact of early and late stage $\mathrm{R} \& \mathrm{D}$ cooperations on non-treated firms' level of activity in the technological and product market, one and two periods after forming a $\mathrm{R} \& \mathrm{D}$ cooperation. Number of previous early and late stage cooperations are used as an instrument. Standard errors are shown in the parenthesis. ${ }^{* * *},{ }^{* *}$ and ${ }^{*}$ denote $99 \%, 95 \%$ and $90 \%$ level of confidence. 
Table 9: Average treatment effect: impact of early/late stage R\&D cooperations on technology and product markets

\begin{tabular}{cclll}
\hline \hline \multicolumn{5}{c}{ Technological and product market level of activity (ATE(x)) } \\
\hline Early stage cooperation & $T M A_{t+1}$ & $\begin{array}{l}0.0362^{*} \\
(0.114)\end{array}$ & $P M A_{t+1}$ & 0.0524 \\
& & & $(0.001)$ \\
& $T M A_{t+2}$ & $\begin{array}{l}0.0622^{* * *} \\
(0.000)\end{array}$ & $P M A_{t+2}$ & 0.0485 \\
& & & & $(0.049)$ \\
Late stage cooperation & $T M A_{t+1}$ & 0.0176 & $P M A_{t+1}$ & $0.0102^{* *}$ \\
& & $(0.022)$ & & $(0.009)$ \\
& $T M A_{t+2}$ & $0.0160^{*}$ & $P M A_{t+2}$ & -0.0904 \\
& & $(0.008)$ & & $(0.009)$ \\
\hline
\end{tabular}

Table 9 presents the instrumental variable estimation results for the impact of early and late stage $\mathrm{R} \& \mathrm{D}$ cooperations on firms' level of activity in the technological and product market, one and two periods after forming a R\&D cooperation. Table 9 presents the average treatment effect. Number of previous early and late stage cooperations are used as an instrument. Standard errors are shown in the parenthesis. $* * *, * *$ and $*$ denote $99 \%, 95 \%$ and $90 \%$ level of confidence. 